\title{
Researching with Families: ethical issues and situations ${ }^{[1]}$
}

\author{
SUE DOCKETT, BOB PERRY, EMMA KEARNEY \\ Charles Sturt University, Albury, NSW, Australia \\ ANNE HAMPSHIRE \\ Mission Australia, Sydney, Australia \\ JAN MASON \& VIRGINIA SCHMIED \\ University of Western Sydney, Australia
}

\begin{abstract}
This article draws on an Australian project engaging with families with complex support needs as their children start school. The project itself is focused on developing collaborative research relationships between families, community support agencies and researchers with the aim of investigating what happens for families during the transition to school. In particular, the project has focused on developing strategies that promote recognition of family strengths, as well as challenges, and that support a positive start to school education. This article reports a range of ethical issues and situations encountered throughout the project. The aim of reporting these is to share some of the critical reflections about the assumptions underpinning the research, ethical engagement with research participants, and the responsibilities researchers have. In particular, the authors share reflections about the nature and implications of conducting research with families, accessing research participants and strategies for engaging with research participants. The approach taken in the project, and this article, reflects assumptions about research as an ethical process and the need for researchers to consider the ethical issues and situations they meet within research contexts.
\end{abstract}

\section{Background}

This article focuses on ethical issues and situations within the context of research investigating family experiences of the transition to school. To provide a context for these issues, two areas are addressed: the background to the research project and the rationale for sharing the experiences of the research team.

\section{The Research Project}

The importance of working with families is one of the underlying tenets of early childhood education. Positive engagement with families is important at all times, but particularly so at points of educational transition when families often seek specific input from educators and other professionals. Times of transition offer opportunities for establishing ongoing patterns of interaction between families and educational settings (McTaggart \& Sanders, 2003). This is particularly the case for families who are positioned as outside the mainstream in some way (Homel et al, 2006).

Despite the recognised importance of family involvement in schools, there is evidence that many families - notably those described as having 'disadvantaged' backgrounds - do not actively participate (Miedel \& Reynolds, 1999; Christenson, 2004). Multiple reasons have been advanced for this lack of participation, including both structural and psychological barriers (Christenson, 2004). 
One consequence is that while 'parental involvement is a robust predictor of a child's success at school ... the reality is that disadvantaged families are least likely to be involved and listened to in school environments' (Bernard van Leer Foundation, 2007, p. 4).

The project from which this article is drawn aimed to facilitate family engagement in education by seeking to understand multiple and diverse experiences of transition, and recognising the strengths that families call upon during this time to help their children make a positive start to school. The project is funded as an ARC (Australian Research Council) Linkage Project, with collaboration between Charles Sturt University, the University of Western Sydney, Mission Australia (MA) and the NSW (New South Wales) Department of Community Services Centre for Parenting Research (DoCS).[2] Members of each of these organisations constitute the research team.

Several theoretical and conceptual bases underpin the project: strengths-based perspectives of working with families (Cowger, 1997; Rapp, 1998; Munford \& Sanders, 2003), ecological theory (Garbarino \& Barry, 1997; Bronfenbrenner \& Morris, 1998) and recognition of the importance of social capital (Putnam, 2000; Beilharz, 2002).

The strengths-based perspective recognises that families demonstrate strengths as well as needs (Munford \& Sanders, 2003). In this approach, families are regarded as experts on their own lives and, with support and assistance, are capable of achieving change (Saleeby, 1997).

Ecological theory (Bronfenbrenner \& Morris, 1998) emphasises the ways in which contexts, as well as the people within them, impact on experience. Ecological models situate responsibility for an effective transition to school with all involved in the process. This broad view recognises that there are many contributors to transition experiences and that the perspectives and expectations of each of these contributors shape those experiences in some way. In these models, transition programs are opportunities for building meaningful and responsive relationships which form the basis for ongoing interactions among children, families and schools (Dockett \& Perry, 2007).

Social capital, 'the cultural resources and interpersonal bonds shared by [community] members' (Jack \& Jordon, 1999, p. 242), plays an important role in promoting family engagement in school. Families who feel a sense of belonging within the school and community, and who feel that they can call on resources to support them, are more likely to engage with schools than those who do not have this sense of connectedness.

Each of these theoretical perspectives has contributed to the project aims of investigating what happens for families with complex support needs as their children start school and developing strategies for families and educators that promote recognition of family strengths, as well as challenges, to support a positive start to school.

\section{Project Participants}

Families who have already engaged in support programs offered by MA and the DoCS, such as the early intervention program Brighter Futures (New South Wales Department of Community Services, 2007) [3], with a child eligible to start school, have participated in the project. These families, in a number of diverse sites across NSW, Australia, have been identified by the partner organisations as having a range of complex support needs. Participation has been offered as an adjunct to involvement in existing programs. It has involved ongoing discussions with researchers (in sites of the participants' choosing) about the transition experiences for the family and child. In this context, we regard the transition as the time before the children start school, when families start to make decisions and seek information about school, through to the actual start of school and the time it then takes for children and families to feel comfortable at school.

Approximately 50 families have been engaged in the project, in 6 diverse locations across NSW. In each site, we have relied on locally based staff from each of the partner organisations to invite families to participate in the project. Researchers have met with family members predominantly mothers - over a period of 6-18 months to discuss what has been happening for them and their family during the transition period. 


\section{Research Approaches}

We adopted qualitative approaches throughout this research, as a means to gain insights into the lived experiences of the participants as they encountered the transition to school. The core of the approach was to engage in in-depth discussions with family members. Each discussion was guided by the participants, as they responded to some open-ended questions about what was happening for their family in relation to the transition to school. The research conversations used in this project involved active asking and listening (Rinaldi, 2005). They occurred in locations identified by the participants - often their own homes. While the in-depth conversations helped the researchers to understand the complex support needs of each family, they also highlighted the strategies adopted by families to enhance their own resilience. Reflecting international research in similar areas, the majority of family participants have been mothers (Crozier \& Reay, 2005).

\section{Developing Shared Ethical Ground}

Before the project commenced, applications were made to the university ethics committee and ethical clearance obtained. This process required consideration of broad ethical principles and assurances that appropriate ethical procedures would be used within the research. However, the conduct of research involving fieldwork generates situations that require individual researchers to interpret and apply these principles in specific situations. Christensen \& Prout (2002) note that:

Fieldwork is likely to bring researchers into contact with different locally constituted ethics. As researchers, we work in social settings with their own local ethical practice. There may be several conflicting practices existing within each setting ... it is this meeting of diverse ethical practices that the researcher has to handle and research ethics will always have to work inside and be integrated into already existing ethical frames. (Christensen \& Prout, 2002, pp. 491-492)

In this project, a range of different ethical practices has been encountered. These include the practices of specific families, organisations, schools and communities. Throughout regular research meetings, we have identified a range of issues and situations which have required individual researchers to interpret ethical principles and practices. As well as individual reflection on these situations, the research team has engaged in discussions with the aim of developing shared responses to situations that have emerged as the research has progressed. Documentation of these discussions has provided the basis for this article. In sharing these with the broader educational, community service and research communities, we invite further discussion about ways in which researchers can develop 'shared ethical ground' (Christensen \& Prout, 2002, p. 492) within research.

\section{Ethical Issues and Situations}

The research project involved close social interactions with people over time. These interactions have occurred in a variety of contexts and provided multiple instances in which ethical issues and situations have arisen and decisions have been made by researchers. Each of these situations and decisions has been the subject of critical reflection as we have sought to turn 'a given into a question' and to transform 'a group of obstacles and difficulties into problems to which the diverse solutions will attempt to produce a response’ (Foucault, 1997, p. 118).

The issues and situations encountered include:

- establishing shared understandings among the research team;

- accessing research participants;

- engaging with families in positive and respectful ways;

- compensation for participants;

- examining potential consequences of research participation; and

- the impact of the research on researchers. 


\section{Establishing Shared Understandings}

The research team is interdisciplinary, involving researchers with educational, research, social work and parenting backgrounds, and organisations with a variety of roles and responsibilities. Each of the researchers and organisations brings to this research their own understandings of ethical research and their own experiences of working with families. The beginnings of establishing shared ethical ground came from discussions around the terminology used within the project and the role of the research team.

Terminology. There is a great deal of research relating to families described as 'disadvantaged', 'at risk' and/or 'vulnerable'. There are many definitions of these terms. For example, Nyamathi (1998, p. 65) defines 'vulnerability' in terms of those who are 'impoverished, disenfranchised, and/or subject to discrimination, intolerance, subordination and stigma'. While many of the families involved in the project could be described using these terms, the negative assumptions inherent in such descriptions were at odds with the strengths-based theoretical position we had adopted. More importantly, the families with whom we were working did not characterise themselves in such ways. Problematising the ways in which families were positioned, by themselves and others, and questioning the assumptions underlying the description of these families resulted in the decision to adopt different terminology - that of 'families with complex support needs'.

Inherent in the project are multiple definitions of 'complex support needs', each of which is socially and contextually constructed. For example, the DoCS (New South Wales Department of Community Services, n.d.) defines families with complex support needs as experiencing at least one of the following characteristics: domestic violence; parental drug and alcohol misuse; parental mental health issues; a lack of extended family or social support; parents with significant learning difficulties or an intellectual disability; and/or child behaviour management problems. While this definition invokes a range of assumptions, it also highlights the diversity of situations and contexts that impact on families and family functioning. Partly to promote critical reflection about what constitutes complex support needs, and partly because we did not want to limit participation in the project, we have relied on the collaborating staff from our partner organisations to invite the participation of families they recognised as having complex support needs and whom they believed would benefit from involvement in the project. This decision has meant that different groups of participants have been recruited in different geographical areas.

The political nature of research is highlighted by explorations of different definitions of 'complex support needs'. For example, in a political landscape of resource allocation, how families are defined and positioned can have a major impact on their access to resources and support, as well as on the nature of interactions they have with service providers. In some instances, the thresholds for accessing support and assistance are very high, with the outcome that many families with complex needs may not be eligible (Barrett, 2008). Consideration of what constitutes complex support needs as well as, within that, what constitutes the most complex support needs echoes Foucault's (1972) call for the examination of the divisions or groupings with which we have become familiar as a means of challenging the taken-for-granted.

Role of the research team. The research team is diverse - both in terms of the researchers involved and the organisations represented. Appropriate roles for the researchers - and the organisations have been the subject of regular discussion. For example, in NSW, the DoCS is the organisation to which reports of suspected child abuse or neglect are made. Much discussion has ensued about how the research team should work with the DoCS in this role, while at the same time not appearing (either to the DoCS or to families) as another mechanism for the surveillance of families. While anxious not to be regarded as an arm of the DoCS, the research team was concerned to establish shared expectations about responding to potentially abusive situations. According to current NSW legislation (New South Wales Government, 1998), researchers are not nominated as mandatory reporters of suspected child abuse or neglect. This position raised a number of ethical issues where mandated requirements did not match the obligations felt by researchers. To resolve these issues, we drew on the work of other research teams [4] to adopt a protocol that outlined a series of steps to be taken by researchers, in collaboration with the DoCS, in relation to suspected child abuse and neglect. The protocol established some parameters for contacting the DoCS to 
discuss concerns about child abuse and neglect, through to steps in making a formal notification. Nevertheless, as a research team we have continued to have ongoing discussions about our roles and responsibilities, experiencing the doubts and uncertainties that underpin critically reflective practice.

Sometimes, individual researchers have had specific responses to individual family situations that prompted lengthy discussions among the team. For example, having encountered a family in dire financial circumstances, should a researcher organise some assistance? Is offering financial assistance any different from offering practical assistance?

\section{Accessing Research Participants}

The research project has relied on accessing a range of participant families who fall within the various definitions of having complex support needs. Accessing potential participants has required close collaboration with agencies in each site, often at a time when these agencies have been implementing new programs, trying to establish services or building a client base in specific areas. Our additional request for help identifying families has involved meeting with many staff from the partner organisations across various sites, often over an extended period.

In each of the communities in which the research was conducted, staff from partner organisations have been actively involved in promoting engagement in the project as an additional avenue for families to seek support. The strategy of gaining access to research participants through known agencies seeks to build on established personal relationships. This model of communityagency-academic collaboration (Benoit et al, 2005) between researchers, support agencies and community organisations has a number of advantages, including bringing together a research team with a range of expertise and a range of practitioners who have an in-depth knowledge of the communities and people with whom they work. One strength of university-communityorganisation collaborations is their ability to draw on both local expertise as well as a research base (Homel et al, 2006). However, one of the challenges of this approach continues to be the association of the research and the researchers with existing programs of the partner organisations. For example, while conscious of positioning the research outside the surveillance structures often associated with the DoCS, several participants tend to use the jargon of welfare systems, suggesting that to them we were regarded as another part of that same system.

A further challenge has been that in some communities, the research project has occurred at the same time as new projects (such as Brighter Futures) have been in their establishment phase. A consequence has been that the research project has not necessarily been a priority for some partner organisation staff. From an ethical stance, the researchers have not felt comfortable putting pressure on partner organisation staff to recruit participants, but have also been aware that the project cannot progress without their assistance. In general, the researchers have spent time building relationships with staff from partner organisations, often interacting with small numbers of families, until such time as partner organisation staff are comfortable with the researchers and the project, and sufficient trust has developed for other families to be introduced to the project.

Gatekeepers. Several factors influenced the decision to work with and through agencies. These included recognition of the importance of existing relationships between families and agencies; expectations that partner organisation staff would understand the context for families with whom they were working; and awareness of the nature of the research.

While partner organisation staff have provided contacts with families for the project, they have also acted as gatekeepers, facilitating access to some families and not others. As was expected, staff from partner organisations have made decisions about which families would benefit from being involved in the project, or would be willing to participate. We have also been aware that in some sites, a 'filtering' process has occurred. For example, in one site the partner organisation manager indicated that, because there was the potential for interviews to be conducted in family homes, she had omitted families where violence was an issue. In current social and political climates where agencies and services are under an intense spotlight, such decisions are understandable. Nevertheless, as noted in overseas studies (Tidmarsh et al, 2003), they impact on who participates in the research, as well as the potential research outcomes. 
As the project has progressed and trusting relationships have been built between partner organisation staff and the researchers, a gradual easing of the gatekeeper role has been evident in some sites. While this is regarded as a positive outcome, the issue of who is represented in the research remains an ongoing focus of discussion.

Working effectively with staff from partner organisations has involved recognising the demands of their professional roles and their commitment to the families with whom they are working. In some instances, it has been clear that staff have been protective of both the researchers and the families. Similar to overseas research (Tidmarsh et al, 2003), staff have been reluctant to involve families who were perceived to be 'in crisis', when they have been in the initial stages of developing a relationship with families, or when they were not sure that there would be any immediate gain for them, their service, or their clients through participating.

Effective negotiation with gatekeepers has involved the researchers taking the time to meet with staff from partner organisations, describing the project and being prepared to work through issues in particular sites. In some sites, staff turnover has presented some difficulties, particularly when staff who have agreed to be involved in the project have left and negotiations with new staff have been needed.

In some situations, we have obtained agreement for agencies to work with the project at managerial level (one level of gatekeeping), only to have this not transferred to the actual service level (the next level of gatekeeping). The ethical management of such situations has been based on building trusting relationships - and in such cases, recognising the demands and expectations of all involved. Regardless of the reason for gatekeeping, Scott (2005, p. 137) reminds us that 'attempts to "crash through the gate" can cause a serious breakdown in communication and collaboration'. Just as it has been important to develop trusting relationships between families and researchers, it has been equally important to establish trusting relationships with the staff from partner organisations who have provided access to participants.

One outcome of this approach has been that a major part of the implementation of the project has revolved around contact with staff from partner organisations. It has been critical to ensure that they were aware of discussions and developments and that their input was incorporated. Several research decisions have been made on the recommendations of these staff such as recruiting families - and other decisions have been made taking these staff into account such as when and where research conversations with families took place.

\section{Engaging with Families}

The research project has, as its core, a commitment to engaging with families in positive and respectful ways. Integral to this have been strategies to ensure that participants have provided informed consent and commitments to build relationships based on trust and rapport. Aligned with these have been ethical issues and situations related to engagement with families.

Informed consent. Ensuring that research participants understand what is being asked of them in a research project and protecting their right to withdraw at any time are critical elements of all social research. Recognising that our research participants are often marginalised in a range of ways, and that the research could be identified with intervention services, we have implemented strategies to ensure that gaining informed consent has been an ongoing, renegotiable process. Cutcliffe $\&$ Ramcharan (2002) refer to this as 'process-consent'.

Working through the processes of seeking informed consent has, at times, been a lengthy process. However, as it is the basis of developing trusting relationships, it has also been an important process. Each family participant in the project was already engaged in some way with existing support programs. They have been contacted by staff from partner organisations and invited to join the project. In most instances, these staff have organised an initial meeting time and location. This meeting provided an opportunity for family members to seek further details about the project, its aims and what was involved. Depending on the preference of the involved family members, agency staff were sometimes present at this meeting. When families elected to be involved in the project, they were invited to complete a consent form (which they could take away 
to seek advice or think about) and a further meeting was organised. The aim of this process was to ensure that people understood what was being asked of them and that they had a genuine choice about participation. It also provided a situation where family contact details remained confidential to the agency, and families had the opportunity to refuse participation by notifying partner organisation staff, rather than the researchers.

There have been some instances in the project where more direct contact between the researchers and participants has been involved, after initial introductions were made and participants indicated their willingness to continue to meet with the researchers. There have also been some instances where families participated in the first meeting, but then chose not to have any further involvement in the project. Regardless of the decision made by families, the aim has been to offer a genuine choice. However, a number of our reflexive discussions have centred on whether or not what we perceived as a choice was interpreted in the same way by families.

The research decisions underpinning this approach have been based on respecting the relationships that partner organisation staff already had with families and aiming to provide genuine opportunities for families to find out about the project. However, we are aware that even for families already engaged with support agencies, resources were limited and we cannot preclude the possibility that some families felt pressured to participate. Indeed, as we have developed relationships with the families over time, and reflected with them on their involvement, we are aware that this has been the case. It has also been suggested that some families became involved in the project as a way of levering access to other forms of support, exerting their own power. The process of critical reflection reminds us of Foucault's position that power relationships underpin many interactions as different groups, agencies and discourses intersect (Danaher et al, 2000).

Relationships based on trust and rapport. In order to work successfully with practitioners and with families, it has been critical to build relationships based on trust and rapport. In this project, we define 'rapport' as developing a relationship where researchers are trusted by research participants as someone with whom they are comfortable sharing their experiences (Miller \& Tewksbury, 2001). For example, in one site where participants met as a small group, the researchers were aware of a recent critical incident that had touched many of the participants. While the group discussion started with the focus of the research project, it soon became an opportunity for participants to share their reactions and responses to this incident. At the conclusion of the session, the researchers and participants both recognised the importance of being able to share experiences in a safe and supportive conversation. While issues around their children starting school were not the major focus of this session, it did serve to form the foundations for further conversations.

Building relationships takes time and is not necessarily an easy or straightforward process. It is reasonable that families may be sceptical of the research and motives of the researchers, and it may also be that families have been engaged in other research which has not necessarily had positive outcomes. Liamputtong (2007) emphasises the importance of building relationships over time, rather than engaging in what is described by Wadsworth (1984) as a 'data raid' - where researchers enter a site, gather as much data as possible and then leave, and participants never hear of the results, outcomes or implications.

Trust has to be earned by researchers, rather than bestowed. Introductions to families through staff from partner organisations have provided an initial contact through a trusted mediator. However, as researchers we have remained aware that establishing relationships based on trust carries obligations and that trust also carries with it an exposure to risk (Goodfellow, 2006). Obligations include fulfilling commitments - for example, when information was promised, it was important to have it delivered; when meeting times were established, the researchers needed to be there. This latter point presented some challenging ethical situations. For example, what is appropriate action when researchers are at the designated meeting, but the family member is not? At what point do researchers stop trying to arrange meetings, if multiple attempts to meet have not worked? In some instances, up to four meetings were organised before an actual meeting occurred. Does continuing to seek opportunities to meet constitute a form of coercion, or is it a sign of perseverance from researchers, indicating that they are genuinely interested in meeting with the family? Or could it reflect the complexity of life for some families? In order to answer such 
questions, the researchers often relied on the background knowledge of the staff from the partner organisations.

A further obligation involves reciprocity. Building relationships based on trust can be facilitated by a sense that both researcher and participant have something to gain from the relationship. In this project, we have been willing to share our expertise about the transition to school when families have sought this information. For example, we have had lengthy discussions with several parents about children's readiness for school and what this means, and been able to direct participants to a range of locally available and contextually relevant information. Liamputtong (2007) suggests that the notion that researchers can give something back to participants can help to reduce the power inequalities inherent in research. In our research team discussions, we have noted that we hope this is the case, though there remains considerable doubt that providing 'expert' advice negates issues of power.

Given the focus of developing respectful, trusting relationships, the researchers were well aware of the implications of removing themselves from these relationships when the project ended. To facilitate this, ongoing feedback about the project was provided to both families and staff from partner organisations, and expectations about the time frame of the project were discussed. To mark the final meeting with the family, a package of materials was developed. It consisted of some items to mark the child's start to school (such as a drinks bottle, pens and library bag) and information for families (a service directory, information about school). The package provided a focus for discussing changes in the relationships that had been developed. With one family, it gave an impetus, or perhaps made it necessary, to ask the family if they wanted to extend the research relationship to a second child eligible to start school the following year, when she wanted to share the package her brother received.

Relationships that reflect trust and reciprocity can also involve direct requests for help from participants (Fontana \& Frey, 2005). These requests presented ethical issues for the researchers, who were conscious of influencing the research itself, wary of setting up relationships of dependence from which they would have to withdraw, as well as judging whether or not they were capable of providing the help being sought. Daly (1992) notes that as researchers, we enter the lives of families and invite them to share their experiences in order for us to gain an understanding of what life is like for them. By engaging with families in this way, Daly argues that we set up relationships based on a 'fair exchange', and because of this we should expect some requests for information or assistance. Liamputtong (2007, p. 62) extends this view by suggesting that researchers 'should be prepared to provide the information the participants need or to direct them to other relevant resources including reading materials or referrals to qualified professionals'. As a research team, we did not necessarily anticipate these requests, but did adopt the stance of responding to them whenever possible and discussing the ethical as well as practical elements of doing so. In a number of cases, the relationship with the partner organisations, as well as with families themselves, was critical in determining possible ways to respond to requests for help.

\section{Compensation for Participants}

Whether or not participants should be paid or otherwise compensated for their participation is a problematic issue in much research. Some researchers describe payment for participation as a potential form of coercion, particularly for groups of people who do not have a great deal of disposable income (Brody, 1998), or as an inducement which undermines free choice (Hollway \& Jefferson, 2000). Other arguments promote the view that payment provides a means of valuing the contribution of participants (Booth, 1999) and can act as a means of reducing power differentials in research (Hollway \& Jefferson, 2000).

Aware of these contrasting perspectives, the decision was taken to offer the participants an A $\$ 20$ voucher each time they met with the researchers. In determining the monetary value of the voucher, we were conscious of valuing the involvement of participants but at the same time not offering an inducement that was so attractive that it could not be refused. Vouchers retained the element of choice for participants in that they were redeemable in a wide range of stores. As a research team we were conscious that families needed to be afforded the right to choose how the vouchers were used. 
However, both offering and accepting vouchers positions researchers and participants in particular ways. In some instances, the participants declined the vouchers. In one site, staff from the partner organisation explained that two potential participants had chosen not to attend a meeting because they were embarrassed to be regarded as in need of the vouchers. Another participant refused the vouchers, noting that he did not expect to be paid for helping his family.

\section{Potential Consequences of Research Participation}

Families with complex support needs may well be marginalised in any number of ways, and it has been important that this research does not add to this (Flaskerud \& Winslow, 1998; Pyett, 2001). For example, several of the families involved already had children attending school and also had a 'reputation' with staff at the school. In some instances, participating in this project had the potential to confirm the family as a 'problem family'. However, it was also possible that involvement in the project demonstrated to those outside the family that there was a desire to support the child starting school and the potential to challenge this reputation. In deciding how to approach teachers at school about the transition experiences of families and children, we have consciously chosen to adopt the latter approach, emphasising the positives.

In the course of the research conversations with family members, a wide range of sensitive topics was raised. For example, once a trusting relationship had been established, it was not uncommon for family members to describe the nature of their complex support needs and some of the challenges associated with these. As researchers, it has been important for us to consider the potential consequences of disclosure - physical and/or psychological. For example, in instances where family violence is an issue, there can be serious repercussions for family members raising this with outsiders. In other situations, discussions about mental health or well-being and approaches to parenting or discipline encompass psychological threats.

Many discussions of the research team focused on appropriate responses to such disclosures. In some instances, the most appropriate response seemed to be to adopt the role of caring listener. In other instances, suggesting an appropriate avenue for assistance seemed most appropriate. In still other instances, action to prompt intervention (such as reporting child abuse or neglect) was regarded as appropriate. Across the range of situations, having a research team with diverse career backgrounds and experiences, solid relationships with the staff in partner organisations who know the families well, and a previously developed protocol outlining possible actions has been invaluable in reflecting on possible actions and reactions to specific situations. At the same time, these discussions have been invaluable in documenting ethically challenging situations and in provoking the realisation that prescribed sets of ethical practice do not necessarily obviate the need for individual researchers to make ethical choices and decisions within the everyday conduct of their research. In other words, being involved in social research requires individual researchers to accept responsibility for making ethical decisions in specific contexts.

\section{Impact of Research on Researchers}

Just as participation in research can be threatening for participants, research can also present threats for researchers. There are physical safety issues to consider when visiting participants' homes as well as emotional reactions to conversations with participants. Strategies to manage these issues have included working as a research team of two wherever possible, and having regular team meetings which serve as debriefing sessions as well as a chance to share developments in each site. Liamputtong (2007) notes the vulnerability of all researchers and suggests that appropriate emotional support should be an integral part of research design. One specific response to such cautions has been to maintain regular contact with the transcriber of all the research conversations, who accesses the stories and experiences of all the participants in ways that also build close connections. Opportunities for her to converse with the researchers and to debrief have been very important.

Qualitative research approaches that provide opportunities for families to share their lived experiences (Warr, 2004) are integral to sensitive research. Such approaches set the scene for researchers to form relationships with families, become attuned to hearing their voices, and to 
access the interpretations afforded by families (Daly, 1992). In adopting qualitative approaches, we have sought to be explicit about the importance of context and the shared interactions between researchers and researched in constructing meaning (Grbich, 2004). For example, we realise that the very presence of researchers changes a specific context, and constitutes a form of intervention that influences the outcomes of the research. This position lends itself to a critical appraisal of the research process and outcomes, facilitating discussions not only about the lived experiences of the research participants, but also ethical and political factors and the impact of being involved in the research. For example, when visiting one family and hearing of their frustration at accessing specialist services for their disabled child, the researchers have questioned their role - should they become involved or just document the situation? In this instance, after discussions with the family, some inquiries were made and the process of locating appropriate services commenced. Such decisions have reflected the position that in building relationships with participants, researchers often need to engage in reciprocal interaction which may include providing advice or information.

\section{Conclusion}

Continuing research into the transition to school (Dockett $\&$ Perry, 2007; Pianta et al, 2007) has highlighted the importance of children and families making positive early connections with schools. One of the outcomes of this project has been to challenge the view that families, particularly those with complex support needs, are not interested in, or have little to contribute to, their children's education, starting with the transition to school. Indeed, this outcome points to the importance of responding to evidence that families with complex support needs are least likely to be involved and listened to in school environments' (Bernard van Leer Foundation, 2007, p. 4) with calls for schools to adopt more inclusive attitudes to these families.

In attempts to engage with families who have complex support needs in respectful ways over time, we have encountered a range of issues and situations. Both as individuals and as a research team, we have been required to interpret and apply our own understandings of research ethics, developing over time a sense of shared ethical ground. Such interpretations have not always been made with a sense of ease; rather the troubling nature of social research has been highlighted, as have the ethical responsibilities we have as researchers. In sharing some of these issues and situations with the broader educational, community service and research communities, we invite further discussions and reflections.

\section{Acknowledgement}

The authors express their thanks to Samia Michael for her assistance in the implementation of the project.

\section{Notes}

[1] The project reported in this article is funded through an ARC (Australian Research Council) Linkage Grant and with the support of the industry partners, Mission Australia and the NSW Department of Community Services.

[2] This research has been undertaken with assistance from the NSW Department of Community Services. However, the information and views contained in this study do not necessarily, or at all, reflect the views or information held by the NSW Government, the Minister for Community Services or the Department of Community Services.

[3] Brighter Futures is an early intervention program provided in NSW by the NSW Department of Community Services. Information about the program is available at: http:/ / www.community.nsw.gov.au/DOCS/STANDARD/PC_100980.htm

[4] We are appreciative of the advice received from Tracey Simpson (Charles Sturt University) and Professor Jennifer Bowes (Macquarie University) in relation to these issues. 


\section{References}

Barrett, H. (2008) 'Hard to Reach' Families: engagement in the voluntary and community sector. London: Family and Parenting Institute.

Beilharz, L. (Ed.) (2002) Building Community: the shared action experience. Brisbane: Solutions Press.

Benoit, C., Jansson, M., Millar, A. \& Phillips, R. (2005) Community-Academic Research on Hard-to-Reach Populations: benefits and challenges, Qualitative Health Research, 15(2), 263-282. http: / / dx.doi.org/ 10.1177/1049732304267752

Bernard van Leer Foundation (2007) Issue Area Framework Summary. Successful Transitions: the continuum from home to school. http: / / www.bernardvanleer.org/files/frameworks/transitions.pdf

Booth, S. (1999) Researching Health and Homelessness: methodological challenges for researchers working with a vulnerable, hard-to-reach, transient population, Australian Journal of Primary Health, 5(3), 76-81. http: / / dx.doi.org/10.1071/PY99037

Brody, B. (1998) Ethics of Research: an international perspective. New York: Oxford University Press.

Bronfenbrenner, U. \& Morris, P.A. (1998) The Ecology of Developmental Processes, in W. Damon \& R.M. Lerner (Eds) Handbook of Child Psychology: theoretical models of human development, 5th edn, vol. 1, 993-1029. New York: Wiley.

Christensen, P. \& Prout, A. (2002) Working with Ethical Symmetry in Social Research with Children, Childhood, 9(4), 477-497. http: / dx.doi.org/10.1177/0907568202009004007

Christenson, S.L. (2004) The Family-School Partnership: an opportunity to promote the learning competence of all students, School Psychology Review, 33(1), 83-104.

Cowger, C. (1997) Assessing Client Strengths: assessment for client empowerment, in D. Saleeby (Ed.) Common Purpose: strengthening families and neighborhoods to rebuild America, 59-73. New York: Anchor.

Crozier, G. \& Reay, D. (Eds) (2005) Activating Participation: parents and teachers working towards partnership. Stoke-on-Trent: Trentham Books.

Cutcliffe, J.R. \& Ramcharan, P. (2002) Levelling the Playing Field? Exploring the Merits of the Ethics-asProcess Approach for Judging Qualitative Research Proposals, Qualitative Health Research, 12(7), 1000-1010. http:/ / dx.doi.org/10.1177/104973202129120313

Daly, K. (1992) The Fit between Qualitative Research and Characteristics of Families, in J.F. Gilgun, K. Daly \& G. Handel (Eds) Qualitative Methods in Family Research, 3-11. Newbury Park, CA: Sage.

Danaher, G., Schirato, T. \& Webb, J. (2000) Understanding Foucault. Sydney: Allen \& Unwin.

Dockett, S. \& Perry, B. (2007) Transitions to School: perceptions, expectations, experiences. Sydney: University of New South Wales Press.

Flaskerud, J.H. \& Winslow, B.J. (1998) Conceptualising Vulnerable Populations in Health-Related Research, Nursing Research, 47(2), 69-78. http: / / dx.doi.org/10.1097/00006199-199803000-00005

Fontana, A. \& Frey, J.H. (2005) The Interview: from neutral stance to political involvement, in N.K. Denzin \& Y.S. Lincoln (Eds) The Sage Handbook of Qualitative Research, 695-727. Thousand Oaks: Sage.

Foucault, M. (1972) The Archaeology of Knowledge. London: Tavistock.

Foucault, M. (1997) Ethics: essential works of Foucault, 1954-1984, vol. 1. London: Penguin.

Garbarino, J. \& Barry, F. (1997) The Community Context of Child Abuse and Neglect, in J. Garbarino \& J. Eckenrode (Eds) Understanding Abusive Families: an ecological approach to theory and practice, 56-85. San Francisco: Jossey-Bass.

Goodfellow, J. (2006) Early Intervention and the Sensitivities of 'Vulnerable' Families, Developing Practice, 17, 32-39.

Grbich, C. (2004) New Approaches in Social Research. London: Sage.

Hollway, W. \& Jefferson, T. (2000) Doing Qualitative Research Differently: free association, narrative and the interview method. London: Sage.

Homel, R., Freiberg, K., Lamb, C., Leech, M., Batchelor, S., Carr, A., Hay, I., Teague, R. \& Elias, G. (2006) The Pathways to Prevention Project: doing developmental prevention in a disadvantaged community, Trends and Issues in Crime and Criminal Justice, 323. http: / / www.aic.gov.au/publications/current\%20series/tandi/321-340/tandi323/view\%20paper.aspx

Jack, G. \& Jordon, B. (1999) Social Capital and Child Welfare, Children and Society, 13(4), 242-256. http: / / dx.doi.org/ 10.1002/(SICI)1099-0860(199909)13:4\%3C242::AID-CHI565\%3E3.0.CO;2-3

Liamputtong, P. (2007) Researching the Vulnerable. London: Sage. 
McTaggart, P. \& Sanders, M.R. (2003) The Transition to School: results from the classroom, Australian eJournal for the Advancement of Mental Health, 2(3), 1-12. http:/ / www.auseinet.com/journal/vol2iss3/mctaggart.pdf

Miedel, W.T. \& Reynolds, A.J. (1999) Parent Involvement in Early Intervention for Disadvantaged Children: does it matter? Journal of School Psychology, 37(4), 379-402. http: / / dx.doi.org/10.1016/S0022-4405(99)00023-0

Miller, J.M. \& Tewksbury, R. (Eds) (2001) Extreme Methods: innovative approaches to social science research. Boston: Allyn \& Bacon.

Munford, R. \& Sanders, J. (Eds) (2003) Making a Difference in Families: research that creates change. Sydney: Allen $\&$ Unwin.

New South Wales Department of Community Services (n.d.) Families First. http: / www.familiesfirst.nsw.gov.au

New South Wales Department of Community Services (2007) Brighter Futures: program guidelines. http://www.community.nsw.gov.au/docswr/_assets/main/documents/brighter_futures_guidelines.p df

New South Wales Government (1998) Children and Young Persons (Care and Protection) Act 1998. http: / / www.legislation.nsw.gov.au/fullhtml/inforce/act+157+1998+FIRST+0+N

Nyamathi, A. (1998) Vulnerable Populations: a continuing nursing focus, Nursing Research, 47(2), 65-66. http: / / dx.doi.org/10.1097/00006199-199803000-00001

Pianta, R.C., Cox, M.J. \& Snow, K. (Eds) (2007) School Readiness and the Transition to Kindergarten in the Era of Accountability. Baltimore: Paul Brookes.

Putnam, R. (2000) Bowling Alone: the collapse and revival of American community. New York: Touchstone.

Pyett, P. (2001) Innovation and Compromise: responsibility and reflexivity in research with vulnerable groups, in J. Daly, M. Guillemin \& S. Hill (Eds) Technologies and Health: critical compromises, 105-119. Melbourne: Oxford University Press.

Rapp, C. (1998) The Strengths Model: case management with people suffering from severe and persistent mental illness. London: Oxford University Press.

Rinaldi, C. (2005) In Dialogue with Reggio Emilia: listening, researching, and learning. London: RoutledgeFalmer.

Saleeby, D. (Ed.) (1997) Common Purpose: strengthening families and neighborhoods to rebuild America. New York: Anchor.

Scott, D. (2005) Inter-Organisational Collaboration in Family-Centred Practice: a framework for analysis and action, Australian Social Work, 58(2), 132-141. http:/ / dx.doi.org/10.1111/j.1447-0748.2005.00198.x

Tidmarsh, J., Carpenter, J. \& Slade, J. (2003) Practitioners as Gatekeepers and Researchers: family support outcomes, International Journal of Sociology and Social Policy, 23(1/2), 59-79. http: / / dx.doi.org/ 10.1108/01443330310790462

Wadsworth, Y. (1984) Do It Yourself Social Research. Melbourne: Victorian Council of Social Services.

Warr, D.J. (2004) Stories in the Flesh and Voices in the Head: reflections on the context and impact of research with disadvantaged populations, Qualitative Health Research, 14(4), 578-587. http:/ / dx.doi.org/10.1177/ 1049732303260449

SUE DOCKETT is Professor of Early Childhood Education at the Murray School of Education, Charles Sturt University, Australia. Her research interests include educational transitions, children's play, young children and mathematics. Correspondence: Sue Dockett, Murray School of Education, Charles Sturt University, Albury, NSW 2640, Australia (sdockett@csu.edu.au).

BOB PERRY is Professor of Education, Murray School of Education, Charles Sturt University, Australia. He is currently engaged in research involving young children and mathematics, educational transitions and promoting positive education for young Indigenous children, their families and communities. Correspondence: Bob Perry, Murray School of Education, Charles Sturt University, Albury, NSW 2640, Australia (bperry@csu.edu.au).

EMMA KEARNEY is a research assistant in the Murray School of Education at Charles Sturt University, Australia. She works on research projects focusing on how best to support families and communities to promote successful transitions into school, children's participation in research, and 
building child and youth friendly communities. Correspondence: Emma Kearney, Murray School of Education, Charles Sturt University, Albury, NSW 2640, Australia ekearney@csu.edu.au

ANNE HAMPSHIRE is National Manager of Research and Social Policy at Mission Australia, a national community services organisation. Anne has undertaken research in a range of areas including children and families, young people and social capital.

Correspondence: hampshirea@missionaustralia.com.au

JAN MASON is Professor of Social Work and a member of the Social Justice and Social Change Research Group, University of Western Sydney. Her research interests include: childhood, child welfare and child/young people participatory research.Correspondence: jan.mason@uws.edu.au

VIRGINIA SCHMIED is Associate Professor (Maternal, Child \& Family Health) in the School of Nursing and Midwifery \& the Family and Community Health Research Group, University of Western Sydney. She is conducting research in child and family health and well-being, parenting programs, home visiting and integrated service systems.Correspondence: v.schmied@uws.edu.au 